\title{
DERECHO HUMANO A LA SALUD: FUNDAMENTO Y CONSTRUCCIÓN
}

\section{HUMAN RIGHT TO HEALTH: FOUNDATION AND CONSTRUCTION}

\author{
Javier Augusto Nicoletti*
}

RESUMEN

\begin{abstract}
Este artículo da cuenta de cómo la concepción del Derecho Humano a la Salud, que hoy nos es familiar, se ha desarrollado a lo largo de la historia. Es un campo de acción con fundamentación propia, sostenido a partir del análisis de los tres rasgos fundamentales de los Derechos Humanos: el carácter absoluto, la universalidad, la inalienabilidad.
\end{abstract}

PALABRAS CLAVES: DERECHOS HUMANOS * SALUD * DERECHO INTERNACIONAL * CONVENIOS

\section{ABSTRACT}

This article deals with the way the conception of the Human Right to Health, so familiar to us nowadays, has evolved throughout history. Thus it has become an action field with its own foundations, sustained on the analysis of the three fundamental features of Human Rights: their absolute character, their universality and their inalienability

KEY WORDS: HUMAN RIGHTS * HEALTH * INTERNATIONAL LAW * CONVENTIONS

1. LOS RASGOS FUNDAMENTALES DEL DERECHO HUMANO A LA SALUD

"La literatura especializada en Derechos Humanos, señala tres rasgos fundamenta-

Departamento de Humanidades y Ciencias Sociales de la Universidad Nacional de La Matanza-UNLaM. Buenos Aires, Argentina. les de los Derechos Humanos: la universalidad, la inalienabilidad y que son absolutos..." (Laporta, 2001) ¿Es posible expresar esta misma afirmación respecto del Derecho Humano a la Salud?

Investigador categorizado por el Ministerio de Educación, Ciencia y Tecnología. Argentina. javiernicoletti@gmail.com 


\subsection{DERECHO UNIVERSAL}

El rasgo de la universalidad de los Derechos Humanos afirma que se trata de Derechos que todos los seres humanos, cualesquiera que sean las circunstancias en que se encuentren, son poseedores de ellos, simplemente, por su condición humana. La universalidad de los sujetos titulares de Derechos es la que más decididamente invita a situar el discurso de los Derechos Humanos en el ámbito de la Moral, porque se fundamenta en algo que está en la base del lenguaje moral de los Derechos Humanos: la esencial igualdad de todos (Laporta, 2001). A los efectos de la titularidad de los Derechos Humanos, los nombres propios y las descripciones definidas son perfectamente irrelevantes. Nadie tiene esos Derechos por ser quién es, por llamarse como se llama o por ocupar una posición definida en cualquier relación social.

Este rasgo, también puede ser abordado desde el prisma de aquellos obligados a respetar los Derechos Humanos. La obligación de promoverlos, el deber de no violarlos o conculcarlos, es de todos. El derecho de cada uno aparece así unido al deber de todos. Esta consideración es extremadamente interesante pero, también, plantea muchos problemas. Sólo es sencilla cuando se consideran aquellos Derechos que se conculcan o violan mediante acciones de los seres humanos. Entonces, es fácil decir qué hacer: abstenerse de realizar esas acciones, por ejemplo, maltratar o robar. Se trata, pues, de deberes negativos.

Pero si se considera los Derechos Humanos que se violan o conculcan por omisión, entonces para reconocer y realizar esos derechos es necesario determinar no qué es lo que no se debe hacer, sino qué es lo que sí se debe hacer, cuáles han de ser las conductas positivas que lleven al reconocimiento de esos derechos. Los Derechos Humanos se sitúan así ante una amplia panoplia de deberes de hacer cosas, es decir, de deberes positivos, y de deberes de todos, es decir, de deberes generales.

La tesis del carácter básico de la idea de universalidad en la génesis de los Derechos Humanos, se refuerza también al tener presente el pensamiento de uno de los autores clave de la filosofía jurídico-política de la Ilustración, de un pensador que en cierto modo resume $y$ culmina la cultura de ese período: Immanuel Kant. Este sitúa en el centro de su filosofía moral la idea de la universalidad. Su imperativo categórico obligará a actuar a partir de reglas universalizables. Lo que hace que unas reglas de conducta sean morales; lo que distingue, en definitiva, la auténtica de la falsa moralidad es el que sus principios sean susceptibles de universalización.

Pérez Luño (2004) hace referencia a las críticas que avanzan hoy en día en el plano filosófico, político y jurídico contra la universalidad de los Derechos Humanos. Sitúa, en el plano filosófico, al autor francés Jean-François Lyotard con su obra La condición Posmoderna, publicada al declinar la década de los setenta, quien tuvo el acierto de acuñar un término que ha hecho fortuna. Con la expresión posmodernidad, Lyotard quería hacer referencia a ese movimiento de revisión crítica de los valores que habían sido el eje de gravitación del pensamiento moderno. Si la Modernidad se había expresado a través de postulados o valores tales como la racionalidad, la universalidad y la igualdad, en este tiempo la condición posmoderna plantea como valores alternativos, las pulsiones emocionales, el particularismo, la exaltación del ego, el culto a los rasgos singulares de la individualidad y la defensa obsesiva de la diferencia (Lyotard, 1989).

En el plano político, Pérez Luño indica que aquellas premisas que critican el rasgo de la universalidad como nota conformadora de los Derechos Humanos las más de las veces tienen como soporte una actitud de relativismo cultural. La idea de un modelo ideal/universal de cultura o de política capaz de servir de canon para todas las sociedades $y$, en consecuencia, exportable a todas ellas, es una falacia; se trata de una hipóstasis destinada a enmascarar la imposición coactiva y/o ideológica de un modelo histórico y concreto, por tanto, de una forma de particularismo político cultural: el modelo europeo occidental en su versión forjada en la Modernidad (Pérez Luño, 2004).

En otras ocasiones, se apelará a la necesidad de no establecer mecanismos discriminatorios o de evitar cualquier actitud de xenofobia en 
los cauces de tutela de los Derechos Humanos. Desde esta perspectiva se quiere evitar que el ideal de la universalidad actúe como un rodillo que desconozca las diferencias y peculiaridades de los hombres y de los pueblos y que, en consecuencia, ignore la exigencia de establecer mecanismos especiales de protección para quienes sufren situaciones especialmente dramáticas de explotación, marginación o subdesarrollo (De Lucas, 1992). Desde esta óptica no se pretende negar la universalidad de los derechos, sino la utilización abusiva de esa idea para tratar de encubrir las profundas desigualdades reales que existen todavía en el seno de la comunidad internacional (Pureza, 1996). En este plano de relativismo cultural es interesante el aporte de Imbert, el cual alerta que, como se ha denunciado certeramente, el derecho a la diferencia, no puede convertirse en una cómoda coartada que se traduzca en una especie de derecho a la indiferencia (Imbert, 1989).

Desde el punto de vista jurídico, algunos constitucionalistas, al cotejar el Derecho Constitucional comparado de la actualidad, comprueban que los derechos y libertades reconocidos en los diversos textos constitucionales difieren notablemente entre sí. Incluso entre los Estados pertenecientes a la cultura occidental, aquellos que obedecen al modelo político del Estado de Derecho, se dan divergencias notables. Así, mientras en algunos de ellos, los que siguen fieles al tipo del Estado liberal de derecho, sólo reconocen las libertades de signo individual, o sea, los Derechos personales civiles y políticos; en otros, los que obedecen al modelo del Estado social de derecho, amplían el catálogo de las libertades para incluir en él también a los Derechos económicos, sociales y culturales.

La doctrina constitucionalista insiste, al propio tiempo, que en los estados sociales de derecho los derechos sociales no gozan de la misma protección jurídica que las libertades individuales. Desde estos enfoques se indica que la distinción, no necesariamente oposición, entre libertades individuales y derechos sociales se hace patente cuando se considera que los derechos individuales vienen considerados como derechos de defensa de las libertades del individuo, que exigen la autolimitación y la no injerencia de los poderes públicos en la esfera privada $y$ se tutelan por su mera actitud pasiva $y$ de vigilancia en términos de policía administrativa. En cambio, los derechos económicos, sociales y culturales, se traducen en derechos de participación, que requieren una política activa de los poderes públicos encaminada a garantizar su ejercicio y se realizan a través de las técnicas jurídicas de las prestaciones y los servicios públicos.

Pérez Luño (1995) infiere que, dada la heterogeneidad de los derechos reconocidos en los textos constitucionales y del carácter heteróclito de los sistemas de garantía previstos para ellos, no parece que responda a la realidad la idea de la pretendida universalidad de los derechos. Al recapitular el sentido básico de cada una de estas perspectivas pudiera concluirse que mientras para la crítica filosófica la universalidad es impugnada por su carácter ideal y abstracto; para la crítica política se la reputa nociva, porque intenta allanar $y$ desconocer las diferentes tradiciones políticas de las distintas culturas; en tanto que, desde la crítica jurídica se insistirá en que la universalidad es imposible, al no existir un marco económico-social que permitiera satisfacer plenamente todos los Derechos Humanos a escala planetaria.

Según De Lucas (2000), el verdadero reto de la universalidad en orden a hacer posible la democracia y el estado de derecho cosmopolitas es la inclusión, o, mejor, el reconocimiento del otro como tal otro, es decir, como diferente $y$, precisamente por ello, sujeto de la soberanía $y$ de los derechos. Pues bien, si ese es el reto, la primera reformulación de la universalidad se traduce en la prioridad del imperativo de la inclusión del otro; esta inclusión no debiera exigir el precio del vaciamiento de toda identidad diferente, en aras del abstracto reconocimiento sólo de aquel que se adapte a un molde determinado. El imperativo de la universalidad de los derechos humanos no implica ofrecer sólo tolerancia, sino, exige vencer el miedo a la diversidad, venciendo esos condicionamientos $y$, en particular, el que liga ciudadanía y derechos.

El pluralismo no se satisface sólo con la diversidad de opciones en el ámbito de la autonomía individual, de los deseos, preferencias y valores particulares; sino, exige abandonar la presunción de las sociedades conformadas de 
modo uniforme. Esta presunción es manifiestamente infundada $y$ desmentida por la realidad, la cual muestra sociedades crecientemente multiculturales, multiétnicas, multinacionales. Además, exige abandonar la falacia subyacente al ingenuo optimismo que propone un nexo de necesidad causal entre la globalización y el ideal universalista de la Ilustración. La globalización no sigue el mandato de la universalización sino que lo usurpa, como se advierte a propósito de los derechos económicos, sociales y culturales, los cuales son, cada vez más, enunciados abiertamente como mercancías y no como auténticos derechos. Lo universalizado, lo que no tiene fronteras, es el tráfico de mercancías y el flujo de capital financiero.

Dicho esto, se afirma que el Derecho Humano a la Salud debe gozar del rasgo de la universalidad, debido a los siguientes ítems a destacar:

$\diamond$ Se trata de un derecho que los seres humanos, cualesquiera que sean las circunstancias en que se encuentren, son poseedores de este, simplemente, por su condición humana y por la esencial igualdad de todos.

$\diamond$ A los efectos de la titularidad de este derecho, los nombres propios y las descripciones definidas son perfectamente irrelevantes. Es decir, nadie es poseedor del derecho a la salud por ser quién es, por llamarse como se llama o por ocupar una posición definida en cualquier relación social.

$\diamond$ La obligación de promover este Derecho Humano, el deber de no violarlo o conculcarlo, es de todos. Se trata de un deber positivo $y$ general.

\subsection{DERECHO INALIENABLE}

Afirmar el carácter inalienable de los Derechos Humanos implica decir que estos son derechos a los que no se puede renunciar y esto es porque forman parte de la propia naturaleza. El carácter inalienable de los Derechos Humanos fue postulado por John Locke, por razones eminentemente prácticas (Rabossi, 1996). Locke temía que cuando los Derechos
Naturales se tornaran positivos hubiera personas que, por coacciones económicas o políticas, decidieran desprenderse de esos derechos. Es interesante, por lo tanto, destacar que el carácter inalienable de los Derechos Humanos está directamente motivado por consideraciones prácticas que poco tienen que ver con características inscriptas en su naturaleza esencial. Si los Derechos Humanos son concebidos como anteriores a su reconocimiento estatal positivo, es necesaria la admisión de un orden moral y jurídico suprapositivo, es decir, una versión iusnaturalista.

Se dice que son inalienables en el sentido de que no pueden ser renunciados ni revocados por sus propios titulares, es decir, que no pueden ser "enajenados" en el sentido de que el propio titular no está moralmente autorizado para prescindir de ellos. El sistema moral le ha inmunizado incluso contra sí mismo. Como plantea Meyers (1998) "un derecho inalienable excluye que sus titulares se despojen a sí mismos de los vínculos morales con el objeto del derecho porque un titular no puede dejar de tener una legitimación para el bien que le confiere un derecho inalienable".

Para poder corroborar si el Derecho Humano a la Salud es un derecho inalienable cabe recurrir, una vez más, a los comentarios de Laporta (2001). Según este autor, las consideraciones que cabe hacer sobre el rasgo de inalienabilidad son en referencia a problemas de justificación. Al preguntarse acerca de qué derechos son inalienables y qué derechos no lo son, la respuesta sólo puede basarse en argumentos referidos al concepto de persona humana que está en la base de cada concepción moral, a los bienes u objetivos morales que se defiendan o a los ideales sociales que se propugnen. Además, indica que es preciso distinguir la titularidad de un derecho del ejercicio de un derecho. Cualquiera podría decidir no ejercer algún derecho que tuviera, pero lo que no podría hacer es renunciar a ser titular de ese derecho.

Entonces, cabe decir que la concepción de SALUD propugna un ideal social de plenitud $y$ promueve un concepto de persona autónoma, responsable y capaz de renunciar al ejercicio de cualquier Derecho si así le pareciera necesario. Cabe resaltar la característica del Derecho 
Humano a la Salud Mental es que, en caso que se quiera renunciar al ejercicio de este, el problema sería discernir si la renuncia se realiza por propia voluntad o por una patología vinculada a la salud mental del titular $y$, en este caso, es imposible distinguir entre la titularidad y el ejercicio, $y$ en tal caso la inalienabilidad afecta a ambas cosas.

\subsection{DERECHO ABSOLUTO}

El tercer gran rasgo que acompaña $y$ define a los Derechos Humanos es la pretensión de llevar consigo una particular fuerza vinculante. Esto es equivalente a decir que los Derechos Humanos son conjuntos de normas algunas de las cuales no admiten excepciones $y$ que, por ejemplo, imponen algún deber sobre alguien que en ningún caso puede estar autorizado a ignorar (Laporta, 2001).

Es preciso hacer aquí algunos matices, porque no debe confundirse esto con la idea de un deber hacer algo tras la consideración de todos los factores. En toda circunstancia concreta en la que un individuo en particular se pregunta “qué debo hacer?”, va a sopesar todos los factores e ingredientes de la situación y, tras esa deliberación, podría llegar a la conclusión de "debo hacer X". Ese deber es la conclusión de una deliberación práctica y es el resultado de una operación de balance y contraste con otros posibles deberes y exigencias que quedan desplazadas por ese deber de hacer $X$. Entonces, ese deber en esa circunstancia puede decirse que no admite ya excepción alguna $y$, en ese sentido, es absoluto.

Pero esto no es lo que se quiere decir cuando se afirma que los Derechos Humanos son Derechos absolutos. Lo que se quiere afirmar con ello es que los Derechos Humanos implican deberes de realizar ciertas clases de acciones, $y$ que tales deberes no admiten excepción alguna a priori. En ningún caso pueden tales Derechos dejar de ser respetados por ninguna acción de la clase de acciones que exigen o prohíben las normas correlativas.

Para apoyar la idea de que pueden haber derechos absolutos se ha distinguido entre satisfacer un derecho, cuando el deber correlativo se cumple, infringir un derecho, cuando el deber correlativo no se cumple, violar un derecho, cuando el derecho es infringido injustificadamente, y sobrepasar un derecho, cuando es infringido justificadamente, es decir, cuando hay justificación para no cumplir el deber correlativo. Un derecho es absoluto cuando no puede ser sobrepasado en ninguna circunstancia, de forma que no puede ser nunca infringido justificadamente, $y$ debe ser cumplido sin ninguna excepción (Gewirth, 1982).

Entonces, ¿es el Derecho Humano a la Salud un derecho absoluto? Sin lugar a dudas. Porque es un derecho que implica el deber de realizar ciertas acciones, no puede ser sobrepasado en ninguna circunstancia y no admite excepciones respecto de su protección y promoción.

\section{EL DERECHO A LA SALUD: UN DERECHO DE SEGUNDA GENERACIÓN}

Afirmar el carácter histórico de los Derechos Humanos implica según Ansuátegui (2000), introducir una dimensión de relativismo en su concepción, porque depende en última instancia de la voluntad y del compromiso de un poder político institucionalizado para provocar la positivización en los textos jurídicos. Según esta línea, los derechos podrían entenderse como realidades cambiantes que se diferenciarían en su estructura y contenido dependiendo de las condiciones históricas. Por ejemplo, según su diferente inspiración ideológica (liberales, sociales); según la transformación del papel del Estado en relación con los derechos y los distintos criterios de legitimidad que se aplican al respecto (abstención, intervención), lo cual está vinculado a las técnicas de protección y a las sucesivas "generaciones» de derechos; según el desarrollo y expansión de valores que nutren $y$ ayudan a fortalecer su fundamento; según la diferente función que han ido desarrollando los derechos en sociedad (derechos exclusivamente frente al Estado y derechos también vinculantes en las relaciones entre particulares), etcétera.

Dado que los Derechos Humanos no son etéreos, puesto que protegen bienes de la persona que se consideran fundamentales, requieren 
de un marco institucional político y jurídico que los haga verdaderamente operativos. Ese marco es la llamada sociedad democrática, entendiendo por esta, en términos generales, una sociedad libre y plural. Ahora bien, como sabemos, las llamadas "sociedades democráticas" han sido objeto de cambios y evoluciones a lo largo de la historia y, uno de sus pilares - los Derechos Humanos - también han ido desarrollándose en etapas sucesivas.

Estos, en tanto construcción histórica, surgieron centrados en el campo de los Derechos Civiles y Politicos (derechos de primera generación): los Derechos civiles responden a la libertad individual de conciencia, de pensamiento y de expresión; los Derechos politicos responden a la posibilidad de participación política de todos los individuos. Posteriormente, surge una creciente conciencia universal acerca de la necesidad de delimitar y proteger, además, a los llamados Derechos económicos, sociales y culturales (derechos de segunda generación): acceso al bienestar social, a la salud, al trabajo, a la vivienda y a la educación.

En principio esta distinción de categoría en los Derechos Humanos tiene como diferencia principal el modo en que son considerados. Los Derechos civiles y políticos eran susceptibles de aplicación inmediata y requerían obligaciones de abstención por parte del Estado; mientras que los Derechos económicos, sociales y culturales debían ser implementados por reglas susceptibles de aplicación progresiva, con obligaciones positivas implícitas. Los Derechos civiles y políticos eran considerados como derechos frente a los poderes públicos, como límite impuesto a la arbitrariedad del Estado; los Derechos económicos, sociales y culturales se plantean, por el contrario, como exigencias de los individuos o de los grupos frente al Estado, a fin de que este proporcione los medios que hagan posible una vida humana digna o un nivel de vida adecuado.

La clasificación de los derechos fue gestando una dualidad cada vez mayor considerando:

$\diamond$ Los derechos sociales, la dignidad de la persona humana en relación con un hombre situado social e históricamente $y$ a necesidades concretas; a diferencia de los derechos individuales, para los cuales la persona era considerada abstracta - un hombre genérico-, encerrada en un esquema racionalista (el propio del individualismo iluminista).

$\diamond$ Los derechos sociales como derechos que tienen un origen histórico y social concreto; a diferencia de los derechos individuales entendidos como derechos superiores $y$ anteriores al Estado.

$\diamond$ Los derechos sociales con la finalidad de pormenorizar las exigencias del valor de igualdad; mientras que los derechos individuales servían para especificar ante todo, aunque no exclusivamente, el valor de la libertad.

Sin embargo, existe una estrecha relación entre la vigencia de los Derechos civiles y políticos y la de los Derechos económicos, sociales y culturales, por cuanto las diferentes categorías de derechos constituyen un todo indisoluble que encuentra su base en el reconocimiento de la dignidad de la persona humana. En la Conferencia Internacional de Derechos Humanos de Teherán de 1968, para lograr una superación de esta dualidad inicial, se proclamó la indivisibilidad de los Derechos Humanos, afirmándose que para alcanzar la plena realización de los Derechos cívicos y políticos es indispensable el goce de los Derechos económicos, sociales y culturales. Se afirma en el artículo $5^{\circ}$ que para que pueda alcanzarse el goce de la máxima libertad y dignidad para la humanidad, es preciso que las leyes de todos los países reconozcan a cada ciudadano, sea cual fuere su raza, idioma, religión o credo político, la libertad de expresión, de información, de conciencia y de religión, así como el derecho a participar plenamente en la vida política, económica, social y cultural de su país.

Los Derechos de Segunda Generación se convierten en condición necesaria para ejercer $y$ poder hacer efectivos los demás derechos, porque su posesión o carencia determinan los mínimos de una vida digna y el ser incluido o excluido de la sociedad. Los derechos fundamentales de carácter liberal y democrático relacionados con las libertades 
no pueden alcanzar su cumplimiento si no quedan conectados a los Derechos económicos, sociales y culturales. Sin la realización de estos, aquellos quedarían expuestos como meras declaraciones retóricas (Gimeno Sacristán, 2001).

El Derecho Humano a la Salud es considerado como un derecho de los denominados Derechos Humanos de Segunda Generación, comprendido en el marco de los Derechos Sociales, Económicos y Culturales.

El Pacto de Derechos económicos, sociales y culturales, da cuenta de que estos derechos tienen una doble dimensión: objetiva $y$ subjetiva. En sentido objetivo, pueden entenderse como el conjunto de normas a través de las cuales el Estado lleva a cabo su función equilibradora de las desigualdades sociales. En su sentido subjetivo, podrían entenderse como las facultades de los individuos y de los grupos a participar de los beneficios de la vida social, lo que se traduce en determinados derechos. Referirse a Derechos Económicos, Sociales y Culturales implica referirse a una cuestión ligada a la subjetividad, porque la sociedad y la cultura contienen significados esenciales para la construcción de un proyecto propio de desarrollo humano.

Para hablar acerca de la Salud es necesario adentrarse en un aspecto básico e indispensable de la vida del hombre: el Derecho Humano a la Salud es considerado un Derecho Fundamental. Poder vivir dignamente, tener un reconocimiento en el propio contexto social, contar con un mínimo de garantías sociales, etc., requiere que el ser humano tenga garantizado este derecho.

\section{LOS INSTRUMENTOS JURÍDICOS DEL DERECHO HUMANO A LA SALUD}

Dicho esto, los Derechos Humanos - primera y segunda generación - compartirían un elemento común que posiblemente sea el rasgo que caracteriza el concepto de Derecho a lo largo de la historia: la de constituir mecanismos o instrumentos, cauces a través de los cuales se materializan las exigencias de los valores de dignidad, igualdad y libertad que los fundamentan, $y$ de acuerdo con ellos desarrollan determinados modelos de ordenación social que se plasman en fenómenos de índole jurídico, político y moral.

A partir de aquí, se abordarán los fenómenos de índole jurídico que ratifican el Derecho Humano a la Salud, elaborando un recorrido al nivel de los instrumentos internacionales.

\subsection{LOS INSTRUMENTOS JURÍDICOS INTERNACIONALES}

$\diamond$ La Declaración Universal de Derechos Humanos proclama en su artículo 25, Inciso $1^{\circ}$, que toda persona tiene derecho a un nivel de vida adecuado que le asegure, así como a su familia, la salud y el bienestar, $y$ en especial la alimentación, el vestido, la vivienda, la asistencia médica y los servicios sociales necesarios.

$\diamond$ En el Protocolo de San Salvador se señala en el Preámbulo que recordando que, con arreglo a la Declaración Universal de los Derechos Humanos y a la Convención Americana sobre Derechos Humanos, sólo puede realizarse el ideal del ser humano libre, exento del temor $y$ de la miseria, si se crean condiciones que permitan a cada persona gozar de sus derechos económicos, sociales y culturales, tanto como sus derechos civiles y políticos.

En el Artículo Décimo, del mismo Protocolo, se declara que:

1. Toda persona tiene derecho a la salud, entendida como el disfrute del más alto nivel de bienestar físico, mental y social.

2. Con el fin de hacer efectivo el derecho a la salud los Estados Partes se comprometen a reconocer la salud como un bien público y particularmente a adoptar medidas para garantizar este derecho.

$\diamond$ En la Convención Americana sobre Derechos Humanos de 1969, se hace referencia a que toda persona tiene derecho a que se respete su integridad física, psíquica y moral (Parte I, Capítulo II, Artículo V, Inciso I). 
$\diamond \quad$ En la Convención sobre los Derechos del Niño, se reconoce el derecho del niño al disfrute del más alto nivel posible de salud $y$ el acceso a servicios para el tratamiento de las enfermedades y la rehabilitación. Los Estados Partes se esforzarán por asegurar que ningún niño sea privado de su derecho al disfrute de esos servicios de salud, haciendo hincapié en el desarrollo de la atención primaria de la salud, la orientación a los padres y los servicios en materia de planificación de la familia. Además, se comprometen a promover y alentar la cooperación internacional con miras a lograr progresivamente la realización del derecho, teniendo en cuenta las necesidades de los países en desarrollo.

En el Artículo 25, los Estados Partes reconocen el Derecho del niño, que ha sido internado en un establecimiento, por las autoridades competentes para los fines de atención, protección o tratamiento de la salud física o mental.

$\diamond$ En la Convención Internacional sobre la Eliminación de todas las formas de Discriminación contra la Mujer, el Artículo 12, refiere a que los Estados Partes adoptarán todas las medidas apropiadas para eliminar discriminación contra la mujer en la esfera de la atención médica, a fin de asegurar, en condiciones de igualdad entre hombres $y$ mujeres, el acceso a servicios de atención médica.

El problema de fondo relativo al Derecho Humano a la Salud es hoy, no tanto el de justificarlos, como el de protegerlos. No es un problema filosófico el de los Derechos Humanos, sino político (Bobbio, 2000). El respeto de la autonomía, de la dignidad, de la integridad $y$, particularmente, la protección y promoción del Derecho Humano a la Salud física, mental y social, representan el gran desafío al cual deben hacer frente con holgura los profesionales en sus diferentes prácticas.

\section{BIBLIOGRAFÍA}

Ansuátegui Roig, F. J. Derechos fundamentales, valores y multiculturalismo. Madrid: Ed. Dykinson, 2005.

- La historia de los Derechos

Humanos. España: Ed. UNIA, 2000.

Bobbio, N. El fundamento de los Derechos Humanos. España: Ed. UNIA, 2000.

Brunner, J. Globalización cultural y posmodernidad. Chile: Editorial Fondo de Cultura Económica, 2004.

Carta Social Europea. España: Ed. Bosch, 1989.

Conferencia Mundial sobre Políticas Culturales. París: Ed. UNESCO, 1982.

Convención Americana sobre Derechos Humanos. Conferencia Especializada Interamericana sobre Derechos Humanos. San José de Costa Rica, 22 de noviembre de 1969.

Convención de los Derechos del Niño. Adoptada y abierta a la firma y ratificación por la Asamblea General en su resolución 44/25, 20 de noviembre de 1989.

Convención Internacional sobre la Eliminación de todas las formas de Discriminación contra la Mujer. Adoptada y abierta a la firma $y$ ratificación, o adhesión, por la Asamblea General en su resolución 34/180, 18 de diciembre de 1979.

De Lucas, J. Europa: ¿convivir con la diferencia? Racismo, nacionalismo $y$ derechos de las minorías. Madrid: Editorial Tecnos, 1992.

La multiculturalidad de los Derechos Humanos. España: Ed. UNIA, 2000. 
Declaración Universal de Derechos Humanos. Organización de las Naciones Unidas (ONU). España: Ed. Icaria, 1998.

Fuster, V. La Ciencia de la Salud. Barcelona: Ed. Planeta, 2008.

Gewirth, A. Are there any absolute Rights? Chicago: The University of Chicago Press, 1982.

Gimeno Sacristán, J. Educar y convivir en la cultura global. Madrid: Ed. Morata, 2001.

Imbert, P. H. L'universalité des Droits de l'Homme. Strasbourg: Conseil de l’Europe, 1989.

Kant, I. (1785). Fundamentación de la metafísica de las costumbres. España: Editorial Espasa-Calpe, 1996.

Laporta, F. El concepto de los Derechos Humanos. España: Ed. UNIA, 2001.

Lyotard, J. F. La condición postmoderna. Madrid: Editorial Cátedra, 1989.

Malagón-Londoño, G.; Galán Morera, R. y Pontón Laverde, G. Garantía de calidad en salud. Madrid: Ed. Médica Panamericana, 2006.

Meyers, D.T. Los Derechos Inalienables. Madrid: Alianza Editorial, 1988.

Pacto Internacional de Derechos Económicos, Sociales y Culturales. Adoptado y abierto a la firma, ratificación y adhesión por la Asamblea General en su resolución 2200 A (XXI), el 16 de diciembre de 1966. Entrada en vigor en 1976.

Peces Barba Martínez, G., con la colaboración de Asís Roig y Barranco Avilés. Lecciones de derechos fundamentales. Madrid: Ed. Dykinson, 2004.
Pérez Luño, A. Derechos Humanos, Estado de Derecho y Constitución. Madrid: Editorial Tecnos, 1995.

- "Las generaciones de Derechos Fundamentales". Revista del Centro de Estudios Constitucionales 10. España, 1991: 203-217.

. Los Derechos Fundamentales. $8^{\circ}$ ed. Madrid: Ed. Tecnos, 2004.

Prieto Sanchís, L. Estudios sobre Derechos Fundamentales. Madrid: Ed. Debate, 1990.

Proclamación de Teherán. Organización de las Naciones Unidas. Proclamada por la Conferencia Internacional de Derechos Humanos en Teherán el 13 de mayo de 1968.

Protocolo adicional a la Convención Americana sobre Derechos Humanos en materia de Derechos Económicos, Sociales y Culturales. OEA, Documentos oficiales, Serie sobre tratados 69, OEA, Ser. A-44 (SEPF), Washington D.C., 1988.

Pureza, J. M. “'Derecho cosmopolita o uniformador? Derechos Humanos, Estado de Derecho y Democracia en la posguerra fría”. Pérez Luño, A. E. (Editor). Derechos Humanos y Constitucionalismo ante el Tercer Milenio. Madrid: Ed. Marcial Pons, 1996.

Rabossi, E. "Cómo teorizar los Derechos Humanos". Pierini, Alicia (Coord.). Pensamiento Crítico sobre Derechos Humanos. Buenos Aires: Ed. Eudeba, 1996.

Soriano Díaz, R. "Valores jurídicos y derechos fundamentales". Madrid: Editorial Alcalá de Guadaira, 1999.

Soriano Díaz, R.; Alarcón Cabrera, C. y Mora Molina, J. Diccionario crítico de los Derechos Humanos. España: Ed. UNIA, 2001. 
